OPEN ACCESS

Edited by: Argiris Symeonidis, University of Patras, Greece

Reviewed by: Roberto Latagliata, Unitelma Sapienza University, Italy

${ }^{*}$ Correspondence: Konstantinos Liapis kosliapis@hotmail.com

Specialty section: This article was submitted to Hematologic Malignancies,

a section of the journal

Frontiers in Oncology

Received: 25 October 2021 Accepted: 29 November 2021 Published: 13 December 2021

Citation: Liapis K and Kotsianidis I (2021) Approaching First-Line

Treatment in Patients With Advanced CMML: Hypomethylating Agents or Cytotoxic Treatment?

Front. Oncol. 11:801524. doi: 10.3389/fonc.2021.801524

\section{Approaching First-Line Treatment in Patients With Advanced CMML: Hypomethylating Agents or Cytotoxic Treatment?}

\author{
Konstantinos Liapis * and loannis Kotsianidis \\ Department of Hematology, Democritus University of Thrace Medical School, Alexandroupolis, Greece
}

Chronic myelomonocytic leukemia $(\mathrm{CMML})$ is a rare clonal haematological malignancy bearing characteristics of both myelodysplastic syndromes and myeloproliferative neoplasms. It primarily affects older people (median age at diagnosis $\sim 72$ years). There are many challenges encountered in its treatment. One striking issue is the lack of strong clinical evidence from large randomized clinical trials for treating this disease. Another issue is that patients with CMML have highly variable outcomes with current treatments. Additional challenges include a wider application of current knowledge, an improved understanding of pathogenesis, development of new therapies, and management of refractory cases/disease progression. It is clear that there is still progress to be made. Here, we review the available first-line treatment options for advanced CMML. Emphasis has been placed on choosing between hypomethylating agents and cytotoxic treatments, on the basis on disease-specific and patient-specific characteristics. A proper selection between these two treatments could lead to a better quality of care for patients with CMML.

\begin{abstract}
Keywords: first-line treatment, hypomethylating agents, azacitidine (5-AzaC), decitabine (DAC), cytotoxic (or antineoplastic) chemotherapeutic agents, hydroxyurea (hu), chronic myelomonocytic leukemia (CMML), myelodysplastic/myeloproliferative neoplasms (MDS/MPN)
\end{abstract}

\section{INTRODUCTION}

Chronic myelomonocytic leukemia (CMML) is a mixed myelodysplastic/myeloproliferative disorder with symptoms that encompass anemia, thrombocytopenia, and splenomegaly (1). CMML has undergone several revisions in its classification reflecting the complexity of the disease. It is subdivided, on the basis of a white-cell count (WBC) of $13 \times 10^{9} / \mathrm{L}$, into dysplastic (MD) and proliferative (MP) variants (2). Outcomes of patients with MP CMML are worse than that of patients with MD CMML. The outcome is also related to the percentage of blasts in the bone marrow (BM). This value is an important part of the diagnosis and is used for a second subdivision into CMML-1 (blasts $<5 \%$ in blood and $<10 \%$ in BM) and CMML-2 (blasts 5-19\% in blood and/or $10-19 \%$ in $\mathrm{BM})(2)$. 
Once diagnosed, the prime consideration is determining whether the patient needs treatment, followed by deciding the appropriate treatment. Ideally, standard management recommendations should be supported by prospective data from randomized controlled trials (RCTs). In reality, however, patients with CMML are often excluded from clinical trials (3). Thus, a major issue is the lack of strong clinical evidence from RCTs for treating CMML (4). The management of CMML, therefore, has evolved without high-quality, data-driven evidence regarding the relative benefit of different treatments.

Another issue to consider is that the outcome of treatment can be highly variable between patients, leading to divergent outcomes in different individuals $(1,4)$. Such variability among patients is multifactorial. Several prognostic scoring systems have been developed in recent years and the biological factors underlying this variability have been investigated (5-9). For example, the CMML-specific Prognostic Scoring System (CPSS) uses four variables (FAB and WHO CMML subtypes; erythrocyte transfusion dependence; and cytogenetic findings) to classify patents into four risk groups (low; intermediate-1; intermediate-2; and high risk) (5). Without doubt, molecular biology has changed the way we manage patients with acute myeloid leukemia (AML) and other myeloid malignancies (1012), but in the case of CMML, full implementation of clinical genomics still has a long way to go and the molecular discoveries have not yet been translated into changes in clinical practice. The clinician who consults patients with CMML is faced with the problem of therapeutic uncertainty and biologic variation.

\section{WHEN TO INITIATE TREATMENT IN CMML}

Not all patients need to be treated immediately. Asymptomatic patients without cytopenia or signs of myeloproliferation (e.g. palpable splenomegaly), as well as those without excess blasts $(<2 \%$ blasts in peripheral-blood and $<5 \%$ in $\mathrm{BM})$, have a relatively stable and more indolent course and a lower probability of transformation to AML. According to the CMML treatment guidelines (published by the European Hematology Association and the European LeukemiaNet), these patients may be observed without treatment until evidence of disease progression or clinical symptoms develop (13). This is a desired approach to avoid treatment complications and the concomitant deterioration in the quality of life (QOL) in patients with asymptomatic, lower-risk CMML. However, this approach is also rooted in the principle that most treatment in CMML is largely directed towards symptom management.

Therapy should be started when CMML is symptomatic or progressive (13). More particularly, treatment is initiated for hemoglobin $<10 \mathrm{~g} / \mathrm{dL}, \mathrm{BM}$ blasts $>5 \%$, platelets $<100 \times 10^{9} / \mathrm{L}$, progressive leukocytosis $\left(>30 \times 10^{9} / \mathrm{L}\right)$, extramedullary involvement (skin lesions, pleural/pericardial effusions, lymphadenopathy), constitutional symptoms (weight loss, fever), and symptomatic splenomegaly or splenomegaly that is palpable $\geq 5 \mathrm{~cm}$ below the left costal margin (4). The key to improving the care of patients with higher risk CMML lies in providing effective therapeutic options that modify the disease course. Their management has two main objectives: to provide effective long-term disease control while maintaining patient's QOL, and to prevent clonal evolution and transition to AML.

\section{USE OF HYPOMETHYLATING AGENTS IN CMML}

The hypomethylating agents (HMAs) 5-azacitidine (AZA) and decitabine (DEC) induce hypomethylation by inhibiting DNA methyltransferase and are widely used in patients with myelodysplastic syndromes (MDS) and AML (14, 15). Although AZA has been approved in the USA for all patients with CMML since 2004 and DEC since 2006, the EU did not approve DEC and restricted the licence of AZA to patients with dysplastic CMML-2 in 2008 (16). Therefore, many patients with CMML in Europe do not receive treatment with HMAs and, when they do, it is often through off-label prescribing. Nonetheless, a growing body of evidence shows that HMAs may play an important role in the treatment of MP CMML (Table 1) (17-25). HMAs can effectively reduce leukocytosis, improve splenomegaly and extramedullary lesions. Subari and colleagues found that HMAs reduced the palpable spleen size to $50 \%$ of the baseline measurement in $45 \%$ of their patients (26). For such treatment, the overall response rate (ORR) is $\sim 50 \%$ (30$60 \%$ ) and complete response (CR) rate $\sim 17 \%$ (10-20\%). Most patients achieve a response after 3 cycles of treatment and median overall survival (OS) is $\sim 29$ months (12-37 months) (4, 13). Given that considerable time may be required for response, hydroxyurea ( $1 \mathrm{~g} /$ day) may be used in patients with proliferative features during the first 3 cycles, until response is attained.

The recent publication of the results of a large multicenter trial showed that patients with higher risk disease i.e. MP CMML, blasts $\geq 10 \%$, and higher risk CMML according to the CPSS, have significantly better outcomes with HMAs compared with hydroxyurea or chemotherapy, whereas patients with lower-risk disease i.e. MD CMML with $<10 \%$ blasts and lower risk CPSS, do not benefit from HMA treatment (27). Although this study provides the only direct, real-life comparison of HMAs with other available treatments, its retrospective and multicenter nature raises concerns about the presence of treatment-selection bias that cannot be overcome with Cox's models. Also, it should be noted that the vast majority of the patients $(>80 \%)$ were treated with AZA and less than $1 \%$ of patients underwent allogeneic hematopoietic-cell transplantation (HCT). Nevertheless, the study provides data that could help clinicians to address real-world questions about care options in CMML.

It is important to note that responses to HMAs are generally not durable, do not reduce mutant allele burdens, and prognosis after loss of response is dismal (median OS 6 months) (28-30). Half the patients with primary or secondary HMA failure transform to AML (31). However, it is equally important to point out the major impact of CR on OS - that is, patients with CMML who achieve CR after HMA treatment have markedly enhanced remission duration and prolonged OS (32). 
TABLE 1 | Phase II studies of hypomethylating agents in chronic myelomonocytic leukemia.

\begin{tabular}{|c|c|c|c|c|c|c|}
\hline Study & $\begin{array}{c}\text { Number of } \\
\text { patients }\end{array}$ & Regimen & $\begin{array}{l}\text { Response } \\
\text { rate }\end{array}$ & $\begin{array}{c}\text { Median sur- } \\
\text { vival (months) }\end{array}$ & Progression to AML & Reference \\
\hline Costa et al. & 38 & $\begin{array}{l}\text { Azacitidine } 75 \mathrm{mg} / \mathrm{m}^{2} / \text { day for } 7 \text { days or } 100 \mathrm{mg} / \mathrm{m}^{2} / \text { day for } 5 \text { days } \\
\text { every } 4 \text { weeks }\end{array}$ & $\begin{array}{l}\text { ORR: } 39 \% \\
\text { CR: } 11 \% \\
\text { PR: } 3 \% \\
\text { HI: } 25 \%\end{array}$ & 12 & NR & (17) \\
\hline Adès et al. & 76 & Azacitidine $75 \mathrm{mg} / \mathrm{m}^{2}$ for $5-7$ days every 28 days & $\begin{array}{l}\text { ORR: } 43 \% \\
\text { CR: } 17 \% \\
\text { PR: } 1 \% \\
\text { Marrow } \\
\text { CR: } 8 \% \\
\text { H: } 17 \%\end{array}$ & 29 & $\begin{array}{l}31 \% \text { after } 1.2 \text { years from } \\
\text { azacitidine initiation }\end{array}$ & (18) \\
\hline Wong et al. & 11 & Azacitidine $75 \mathrm{mg} / \mathrm{m}^{2}$ for 7 days every 28 days & $\begin{array}{l}\text { ORR: } 55 \% \\
\text { CR: } 9 \% \\
\text { Marrow } \\
\text { CR: } 27 \% \\
\text { PR: } 9 \% \\
\text { HI: } 9 \%\end{array}$ & 17 & $18 \%$ & (19) \\
\hline $\begin{array}{l}\text { Drummond } \\
\text { et al. }\end{array}$ & 32 & Azacitidine $75 \mathrm{mg} / \mathrm{m}^{2}$ for 7 days, every 28 days & $\begin{array}{l}\text { ORR: } 17 \% \\
\text { CR: } 7 \% \\
\text { Marrow } \\
\text { CR: } 7 \% \\
\text { PR: } 0 \% \\
\text { H: } 3 \%\end{array}$ & 16 & $\begin{array}{l}33 \% \text { after } 13 \\
\text { months }\end{array}$ & (21) \\
\hline $\begin{array}{l}\text { Tantravahi } \\
\text { et al. }\end{array}$ & 11 & Azacitidine $75 \mathrm{mg} / \mathrm{m} 2$ for 7 days, every 28 days & $\begin{array}{l}\text { ORR: } 45 \% \\
\text { CR: } 27 \% \\
\text { Marrow } \\
\text { CR: } 18 \% \\
\text { SD: } 36 \% \\
\text { PD: } 9 \%\end{array}$ & 30 & $18 \%$ at 2 years & (22) \\
\hline $\begin{array}{l}\text { Santini } \\
\text { et al. }\end{array}$ & 43 & Decitabine $20 \mathrm{mg} / \mathrm{m}^{2}$ for 5 days, every 28 days & $\begin{array}{l}\text { ORR: } \\
47.6 \% \\
\text { CR: } 16 \% \\
\text { Marrow } \\
\text { CR: } 19 \% \\
\text { PR: } 2.4 \% \\
\text { HI: } 9.5 \%\end{array}$ & 17 & $57.5 \%$ after 51.5 months & (25) \\
\hline
\end{tabular}

ORR, overall response rate; $C R$, complete remission; PR, partial remission; HI, hematologic improvement; $S D$, stable disease; PD, progressive disease; NR, not reported.

\section{WHICH PATIENTS ARE LIKELY TO RESPOND TO HYPOMETHYLATING AGENTS?}

The ability to identify individuals who are unlikely to receive therapeutic benefit could facilitate a personalized approach to treatment selection and inform transplant strategies. Although clinical factors are inadequate for predicting responses to HMAs in individual patients, new molecular techniques have identified certain mutational profiles as potential biomarkers, but with conflicting results. In a retrospective series of 174 patients with CMML, patients with TET2 mutations without ASXL1 mutation
( $\sim 25 \%$ of patients) had the highest ORR (66\% versus $47 \%$ for all other genotypes) and CR rate (32\% versus $11 \%$ for all other genotypes) to HMA treatment. Mutations in ASXL1, RUNX1 and $C B L$ were associated with low ORR and poor OS (33). By contrast, the study by Costa and co-workers indicated that ASXL1 and TET2 mutations did not predict response to AZA (17). Clearly, such questions can be answered only by means of dedicated, large-scale cohort studies. Several methodological barriers must be overcome to safely use mutational profiles as predictive biomarkers, as has been recently shown during the development of the new Molecular International Prognostic Scoring System (IPSS-M) for MDS (34). The identification of 
predictors to HMA resistance is the topic of intense research, but it must be emphasized that, in the present context, no established biomarker exists for prediction of response to HMA treatment.

\section{CYTOTOXIC CHEMOTHERAPY FOR CMML}

Treatment should be tailored to the biology of the disease and CMML is known to be relatively resistant to cytotoxic drugs (13). Treatment regimens similar to those used to treat newlydiagnosed AML have been used in CMML. Intensive combinations of anthracycline-cytarabine, cytarabine-topotecan, or regimens including clofarabine have moderate efficacy in CMML $(13,35-37)$. Overall, the results of such treatments have been disappointing with a remission rate of $40 \%$, short remission duration, and relapse rate of $90 \%$. With the advent of HMAs, AML-type chemotherapy is used less frequently in CMML. Yet CR rates with the use of HMAs are lower $(\sim 17 \%)$ than rates achieved with induction chemotherapy $(\sim 40 \%)$. Despite major improvements in supportive care, there is a substantial risk of early death (up to 25\%) and the potential for serious harm in older patients ( $>65$ years) after induction chemotherapy, which means that the risks and benefits of treatment must be weighed carefully when formulating a treatment plan. All considered, chemotherapy remains an option for patients aged $<65-70$ years with minimal impairment of function who have advanced-stage or rapidly evolving disease with $\geq 10 \% \mathrm{BM}$ blasts (i.e. CMML-2). The rationale behind the use of cytotoxic chemotherapy is to reduce BM blasts and aim for CR before HCT. Cytotoxic chemotherapy may also be considered for CMML with NPM1 mutation. In particular, cases with a high NPM1 mutational burden are associated with a higher probability of rapid transition to AML (at a median of 5 months) with myelomonocytic (M4) or monocytic (M5) differentiation and a poorer outcome, even when treated with chemotherapy $(38,39)$. NPM1 mutations are uncommon in CMML occurring in $<5 \%$ of cases and, if found, the alternative diagnosis of AML-M4/M5 with mutated NPM1 should always be borne in mind (2). In contrast, the presence of FLT3ITD (also occurring in $<5 \%$ of cases) does not necessarily herald the onset of AML transformation (13).

\section{ALLOGENEIC HEMATOPOIETIC-CELL TRANSPLANTATION}

This approach remains the only curative treatment of higher-risk CMML. However, it can generally be offered only to a few patients with CMML-younger patients may be offered myeloablative HCT and older patients can be offered reducedintensity HCT from an HLA-identical donor. The conventional upper age limit for HCT is around 70 years.

Several studies have retrospectively analyzed the results of allogeneic HCT in CMML. It emerges that, at the moment, outcomes of HCT in CMML are worse than in MDS: the response rates in CMML have ranged from $17 \%$ to $50 \%$, and treatment-related mortality (TRM) rates have ranged from $12 \%$ to $52 \%$ (40-44). The largest study of HCT to date including 513 patients found a relapse rate of 32\%, non-relapse mortality (NRM) $41 \%$, disease-free survival $27 \%$, and OS $33 \%$ at 4 years. Disease status was the main risk factor for TRM, and the achievement of CR pre-transplant was the only predictor of survival (45).

Since the achievement of CR prior to HCT is the most important prognostic factor for a favorable outcome (45), the members of an expert panel have recommended treatment before HCT, particularly in cases with BM blasts $\geq 10 \%$ and/or intermediate- 2 or high risk CPSS (46). In view of the lack of evidence from RCTs, the best treatment for reducing tumor burden before HCT remains a controversial issue (13, 47, 48). AZA may allow for similar outcomes after HCT as compared with induction chemotherapy $(49,50)$. However, the CR rate with chemotherapy is higher than HMAs (excluding patients with TET2+/ASXL1- mutations), suggesting that chemotherapy may be suitable in selected, younger patients with high blast count. Transplantation should preferably be performed early after diagnosis and after establishing the best possible response.

\section{CYTOREDUCTION WITH HYDROXYUREA}

Single-agent, low-dose chemotherapy (e.g low-dose cytarabine, etoposide, 6-mercaptopurine) gives poor results in CMML (5154). However, hydroxyurea remains an important component of CMML treatment despite its lack of disease-modifying activity. Since the classic study by Wattel and co-workers in 1996 (54), hydroxyurea is used for the control of leukocytosis, organomegaly, visceral involvement and hypercatabolic symptoms associated with advanced-stage, MP CMML. In this study, advanced-stage CMML was defined as presence of either extramedullary disease, excluding enlargement of the spleen and liver, or $\geq 2$ of the following criteria: BM blasts $>5 \%$, neutrophils $>16 \times 10^{9} / \mathrm{L}$, hemoglobin $<10 \mathrm{~g} / \mathrm{dL}$, platelets $<100 \times 10^{9} / \mathrm{L}$, and splenomegaly $>5 \mathrm{~cm}$ below costal margin. The usual dose is $1 \mathrm{~g} /$ day (doubled in case of visceral involvement), escalated up to $3 \mathrm{~g}$ /day in the absence of response after 2 weeks of treatment, and adjusted to maintain WBC 4$10 \times 10^{9} / \mathrm{L}$ (54). Hydroxyurea yields only partial responses, has low efficacy on visceral involvement, may lead to worsening of anemia, and survival is generally poor (median OS 24 months) (54). Prognostic factors for lower response rates and poor OS include unfavorable karyotype (monosomy 7 or complex) and low hemoglobin level (54). In a small, retrospective series of patients with MP CMML, previous hydroxyurea exposure appeared to have a modest negative impact on the response rate to HMA treatment (55), but this finding requires prospective confirmation.

\section{DACOTA TRIAL: A SIMPLE, PHASE 3 RCT WITH COMPLEX QUESTIONS}

The DACOTA trial, a multicenter prospective phase 3 RCT of DEC versus hydroxyurea, included 170 patients with advancedstage, MP CMML between October 2014 and September 2019 
(84 in the DEC group; 86 in the hydroxyurea group). The data presented at ASH showed that although DEC was associated with a higher ORR as compared with hydroxyurea (56\% versus $30 \%$ ), no significant differences between the two groups were noted with respect to OS and event-free survival (EFS) (56). Why, then, patients that have a higher response rate with DEC do not have a superior OS or EFS? One reason might be that one third of patients with hydroxyurea subsequently received HMAs after exiting the study because of disease progression. Another possibility is that the benefit of DEC may be confined to a subset of patients with MP CMML_e.g., patients without ASXL1 mutations and/or patients with higher risk CPSS. Or, perhaps more likely, the better disease control achieved with DEC was offset by more frequent complications and treatment delays. If so, relying on supportive care with prophylactic antimicrobial agents could be a wise decision in these cases. To put the study in perspective, the main conclusion is that, although hydroxyurea remains a valid option, HMAs, given their higher response rate, have the potential to serve as a bridge to allogeneic HCT in patients with advanced-stage, MP CMML.

\section{CONCLUSION}

\section{First-Line Treatment in Patients With CMML: Hypomethylating Agents or Cytotoxic Treatment?}

Although our understanding of the pathophysiology of CMML has improved remarkably, its treatment remains an unmet clinical need. At present, HCT is the only treatment that can induce long-term remission in CMML. Such therapy, however, is not applicable for most patients, since the median age at diagnosis is 72 years (1). Many patients have comorbidities and impaired functional status, which can lead to poor post-transplantation outcomes. In addition, the substantial risks of death and complications associated with this procedure may not justify its use in patients at lower risk. We consider HCT a treatment option for younger and fitter patients who have a poor prognosis or severe symptoms. Improving the efficacy and safety of HCT would allow many more patients to be cured.

Regardless of whether HCT is scheduled, AZA is our preferred treatment option to reduce the leukemic burden and overcome transfusion dependence in patients who need treatment, including patients with MP CMML. Yet we may consider induction chemotherapy for younger patients with adequate organ function and performance status who have advanced-stage or rapidly evolving disease with $\geq 10 \% \mathrm{BM}$

\section{REFERENCES}

1. Patnaik MM, Tefferi A. Chronic Myelomonocytic Leukemia: 2020 Update on Diagnosis, Risk Stratification and Management. Am J Hematol (2020) 95:97115. doi: 10.1002/ajh.25684

2. Swerdlow SH, Campo E, Harris NL, Jaffe ES, Pileri SA, Stein H, et al. WHO Classification of Tumours of Haematopoietic and Lymphoid Tissues. Lyon, France: IARC Press (2017). blasts. Although not approved by the EU, AZA has been widely used for MP CMML for the past 10-15 years. It appears that HMAs have a disease-modifying activity in CMML, but, as is the case of MDS and AML, their effect is temporary and combinations with novel agents targeting different pathways is urgently needed in order to enhance remission duration and prolong OS (57). Current efforts in clinical research focus on the discovery of HMA combination therapies that are intended to provide an improvement in efficacy over HMA monotherapy. An important new drug in combination with HMA is venetoclax, a highly-selective, potent, oral BCL-2 inhibitor. Ongoing clinical trials are evaluating the combination of AZA with venetoclax in higher risk CMML (NCT04160052, NCT03404193). However, a recent study showed that leukemic monocytic cells often develop resistance to venetoclax due to biological properties intrinsic to monocytic differentiation, as they can shift antiapoptotic proteins from BCL-2 to MCL-1, promoting cell survival (58). Additionally, RAS pathway mutations, found in $\sim 11 \%$ at diagnosis (4) but $\sim 35 \%$ at progression/relapse (59), may confer resistance to venetoclax $(57,60)$. The combination of HMAs with other new molecular-targeting agents and monoclonal antibodies is also under investigation in higher-risk CMML (57).

In appropriate circumstances, cytoreduction with hydroxyurea still has a role in the care of patients with CMML. The decision for such treatment should be based on the patient's age, symptoms, comorbidity, and disease status. In our experience, hydroxyurea should be the choice for older patients with advanced-stage, MP CMML without severe anemia, thrombocytopenia, excess marrow blasts, unfavorable cytogenetics, or higher-risk CPSS. The presence of NPM1 mutation ( $~ 5 \%$ of patients) calls for reconsideration of the diagnosis of CMML, as AML-M4 can masquerade initially as CMML, and intensive chemotherapy could be used in younger, fitter patients or combination treatment with azacitidine plus venetoclax in older individuals $(13,60)$.

In approaching first-line treatment in patients with CMML, we might ask another, broader and more unsettling question: how to balance clinical practice between what is known, not known, and uncertain in our knowledge.

\section{AUTHOR CONTRIBUTIONS}

KL searched the literature and wrote the manuscript. IK overreviewed the manuscript. All authors contributed to the article and approved the submitted version. 
6. Itzykson R, Kosmider O, Renneville A, Gelsi-Boyer V, Meggendorfer M, Morabito M, et al. Prognostic Score Including Gene Mutations in Chronic Myelomonocytic Leukemia. J Clin Oncol (2013) 31:2428-36. doi: 10.1200/ JCO.2012.47.3314

7. Patnaik MM, Padron E, LaBorde RR, Lasho TL, Finke CM, Hanson CA, et al. Mayo Prognostic Model for WHO-Defined Chronic Myelomonocytic Leukemia: ASXL1 and Spliceosome Component Mutations and Outcomes. Leukemia (2013) 27:1504-10. doi: 10.1038/leu.2013.88

8. Diamantopoulos PT, Kotsianidis I, Symeonidis A, Pappa V, Galanopoulos A, Gogos D, et al. Chronic Myelomonocytic Leukemia Treated With 5Azacytidine - Results From the Hellenic 5-Azacytidine Registry: Proposal of a New Risk Stratification System. Leuk Lymphoma (2019) 60:1721-30. doi: 10.1080/10428194.2018.1540783

9. Elena C, Gallì A, Such E, Meggendorfer M, Germing U, Rizzo E, et al. Integrating Clinical Features and Genetic Lesions in the Risk Assessment of Patients With Chronic Myelomonocytic Leukemia. Blood (2016) 128:140817. doi: 10.1182/blood-2016-05-714030

10. Papaemmanuil E, Gerstung M, Bullinger L, Gaidzik VI, Paschka P, Roberts ND, et al. Genomic Classification and Prognosis in Acute Myeloid Leukemia. N Engl J Med (2016) 374:2209-21. doi: 10.1056/NEJMoa1516192

11. Döhner H, Estey E, Grimwade D, Amadori S, Appelbaum FR, Büchner T, et al. Diagnosis and Management of AML in Adults: 2017 ELN Recommendations From an International Expert Panel. Blood (2017) 129:424-47. doi: 10.1182/ blood-2016-08-733196

12. Grinfeld J, Nangalia J, Baxter EJ, Wedge DC, Angelopoulos N, Cantrill R, et al. Classification and Personalized Prognosis in Myeloproliferative Neoplasms. N Engl J Med (2018) 379:1416-30. doi: 10.1056/NEJMoa1716614

13. Itzykson R, Fenaux P, Bowen D, Cross NCP, Cortes J, De Witte T, et al. Diagnosis and Treatment of Chronic Myelomonocytic Leukemias in Adults: Recommendations From the European Hematology Association and the European LeukemiaNet. Hemasphere (2018) 2:e150. doi: 10.1097/HS9. 000000000000150

14. Fenaux P, Mufti GJ, Hellstrom-Lindberg E, Santini V, Finelli C, Giagounidis A, et al. Efficacy of Azacitidine Compared With That of Conventional Care Regimens in the Treatment of Higher-Risk Myelodysplastic Syndromes: A Randomised, Open-Label, Phase III Study. Lancet Oncol (2009) 10:223-32. doi: 10.1016/S1470-2045(09)70003-8

15. Dombret H, Seymour JF, Butrym A, Wierzbowska A, Selleslag D, Jang JH, et al. International Phase 3 Study of Azacitidine vs Conventional Care Regimens in Older Patients With Newly Diagnosed AML With $>30 \%$ Blasts. Blood (2015) 126:291-9. doi: 10.1182/blood-2015-01-621664

16. Vidaza (Azacitidine) [Package Insert]. Uxbridge, UK: Celgene Ltd (2019).

17. Costa R, Abdulhaq H, Haq B, Shadduck RK, Latsko J, Zenati M, et al. Activity of Azacitidine in Chronic Myelomonocytic Leukemia. Cancer (2011) 117:2690-6. doi: 10.1002/cncr.25759

18. Adès L, Sekeres MA, Wolfromm A, Teichman ML, Tiu RV, Itzykson R, et al. Predictive Factors of Response and Survival Among Chronic Myelomonocytic Leukemia Patients Treated With Azacitidine. Leuk Res (2013) 37:609-13. doi: 10.1016/j.leukres.2013.01.004

19. Wong E, Seymour JF, Kenealy M, Westerman D, Herbert K, Dickinson M. Treatment of Chronic Myelomonocytic Leukemia With Azacitidine. Leuk Lymphoma (2013) 54:878-80. doi: 10.3109/10428194.2012.730615

20. Fianchi L, Criscuolo M, Breccia M, Maurillo L, Salvi F, Musto P, et al. High Rate of Remissions in Chronic Myelomonocytic Leukemia Treated With 5Azacytidine: Results of an Italian Retrospective Study. Leuk Lymphoma (2013) 54:658-61. doi: 10.3109/10428194.2012.719617

21. Drummond MW, Pocock C, Boissinot M, Mills J, Brown J, Cauchy P, et al. A Multi-Centre Phase 2 Study of Azacitidine in Chronic Myelomonocytic Leukaemia. Leukemia (2014) 28:1570-2. doi: 10.1038/leu.2014.85

22. Tantravahi SK, Szankasi P, Khorashad JS, Dao KH, Kovacsovics T, Kelley TW, et al. A Phase II Study of the Efficacy, Safety, and Determinants of Response to 5-Azacitidine (Vidaza ${ }^{\circledR}$ ) in Patients With Chronic Myelomonocytic Leukemia. Leuk Lymphoma (2016) 57:2441-4. doi: 10.3109/10428194. 2016.1138295

23. Wijermans PW, Rüter B, Baer MR, Slack JL, Saba HI, Lübbert M. Efficacy of Decitabine in the Treatment of Patients With Chronic Myelomonocytic Leukemia (CMML). Leuk Res (2008) 32:587-91. doi: 10.1016/j.leukres. 2007.08.004
24. Braun T, Itzykson R, Renneville A, de Renzis B, Dreyfus F, Laribi K, et al. Molecular Predictors of Response to Decitabine in Advanced Chronic Myelomonocytic Leukemia: A Phase 2 Trial. Blood (2011) 118:3824-31. doi: 10.1182/blood-2011-05-352039

25. Santini V, Allione B, Zini G, Gioia D, Lunghi M, Poloni A, et al. A Phase II, Multicentre Trial of Decitabine in Higher-Risk Chronic Myelomonocytic Leukemia. Leukemia (2018) 32:413-8. doi: 10.1038/leu.2017

26. Subari S, Patnaik M, Alfakara D, Zblewski D, Hook C, Hashmi S, et al. Hypomethylating Agents Are Effective in Shrinking Splenomegaly in Patients With Chronic Myelomonocytic Leukemia. Leuk Lymphoma (2016) 57:17145. doi: 10.3109/10428194.2015.1105371

27. Pleyer L, Leisch M, Kourakli A, Padron E, Maciejewski JP, Xicoy Cirici B, et al. Outcomes of Patients With Chronic Myelomonocytic Leukaemia Treated With non-Curative Therapies: A Retrospective Cohort Study. Lancet Haematol (2021) 8:e135-48. doi: 10.1016/S2352-3026(20)30374-4

28. Alfonso A, Montalban-Bravo G, Takahashi K, Jabbour EJ, Kadia T, Ravandi F, et al. Natural History of Chronic Myelomonocytic Leukemia Treated With Hypomethylating Agents. Am J Hematol (2017) 92:599-606. doi: 10.1002/ ajh. 24735

29. Merlevede J, Droin N, Qin T, Meldi K, Yoshida K, Morabito M, et al. Mutation Allele Burden Remains Unchanged in Chronic Myelomonocytic Leukaemia Responding to Hypomethylating Agents. Nat Commun (2016) 7:10767. doi: $10.1038 /$ ncomms 10767

30. Kotsianidis I, Papageorgiou SG, Pappa V, Galanopoulos AG, Viniou NA, Vassilakopoulos TP, et al. Azacytidine Failure Revisited: An Appraisal Based on Real-Life Data From the MDS Registry of the Hellenic Myelodysplastic Syndrome Study Group (HMDS). Mediterr J Hematol Infect Dis (2019) 11: e2019045. doi: 10.4084/MJHID.2019.045

31. Niscola P, Tendas A, Scaramucci L, Giovannini M, Piccioni D, de Fabritiis P. Acute Myeloid Leukemia Arising From Chronic Myelomonocytic Leukemia During Hypomethylating Therapy. Blood Res (2014) 49:65-6. doi: 10.5045/ br.2014.49.1.65

32. Papoutselis M, Douvali E, Papadopoulos V, Spanoudakis E, Margaritis D, Tsatalas C, et al. Has Introduction of Azacytidine in Everyday Clinical Practice Improved Survival in Late-Stage Myelodysplastic Syndrome? A Single Center Experience. Leuk Res (2014) 38:161-5. doi: 10.1016/ j.leukres.2013.10.015

33. Duchmann M, Yalniz FF, Sanna A, Sallman D, Coombs CC, Renneville A, et al. Prognostic Role of Gene Mutations in Chronic Myelomonocytic Leukemia Patients Treated With Hypomethylating Agents. EBioMedicine (2018) 31:174-81. doi: 10.1016/j.ebiom.2018.04.018

34. Bernard E, Tuechler H, Greenberg PL, Hasserjian RP, Arango Ossa J, Nannya Y, et al. The American Society of Hematology_ 63rd Annual Meeting and Exposition. Molecular International Prognosis Scoring System for Myelodysplastic Syndromes. Blood (2021).

35. Tricot G, Boogaerts MA. The Role of Aggressive Chemotherapy in the Treatment of the Myelodysplastic Syndromes. Br J Haematol (1986) 63:477-83. doi: 10.1111/j.1365-2141.1986.tb07524.x

36. Beran M, Estey E, O’Brien S, Cortes J, Koller CA, Giles FJ, et al. Topotecan and Cytarabine Is an Active Combination Regimen in Myelodysplastic Syndromes and Chronic Myelomonocytic Leukemia. J Clin Oncol (1999) 17:2819-30. doi: 10.1200/JCO.1999.17.9.2819

37. Ghanem H, Garcia-Manero G, Faderl S, Ravandi F, Cortes J, Katragadda L, et al. Outcomes of Patients With Myelodysplatic Syndrome and Chronic Myelomonocytic Leukemia Post Clofarabine Failure. Ther Adv Hematol (2014) 5:29-34. doi: 10.1177/2040620713519742

38. Peng J, Zuo Z, Fu B, Oki Y, Tang G, Goswami M, et al. Chronic Myelomonocytic Leukemia With Nucleophosmin (NPM1) Mutation. Eur J Haematol (2016) 96:65-71. doi: 10.1111/ejh.12549

39. Vallapureddy R, Lasho TL, Hoversten K, Finke CM, Ketterling R, Hanson C, et al. Nucleophosmin 1 (NPM1) Mutations in Chronic Myelomonocytic Leukemia and Their Prognostic Relevance. Am J Hematol (2017) 92:E6148. doi: 10.1002/ajh.24861

40. Kröger N, Zabelina T, Guardiola P, Runde V, Sierra J, Van Biezen A, et al. Allogeneic Stem Cell Transplantation of Adult Chronic Myelomonocytic Leukaemia. A Report on Behalf of the Chronic Leukaemia Working Party of the European Group for Blood and Marrow Transplantation (EBMT). $\mathrm{Br} J$ Haematol (2002) 118:67-73. doi: 10.1046/j.1365-2141.2002.03552.x 
41. Elliott MA, Tefferi A, Hogan WJ, Letendre L, Gastineau DA, Ansell SM, et al. Allogeneic Stem Cell Transplantation and Donor Lymphocyte Infusions for Chronic Myelomonocytic Leukemia. Bone Marrow Transplant (2006) 37:1003-8. doi: 10.1038/sj.bmt.1705369

42. Ocheni S, Kröger N, Zabelina T, Zander AR, Bacher U. Outcome of Allo-SCT for Chronic Myelomonocytic Leukemia. Bone Marrow Transplant (2009) 43:659-61. doi: 10.1038/bmt.2008.366

43. Krishnamurthy P, Lim ZY, Nagi W, Kenyon M, Mijovic A, Ireland R, et al. Allogeneic Haematopoietic SCT for Chronic Myelomonocytic Leukaemia: A Single-Centre Experience. Bone Marrow Transpl (2010) 45:1502-07. doi: 10.1038/bmt.2009.375

44. Park S, Labopin M, Yakoub-Agha I, Delaunay J, Dhedin N, Deconinck E, et al. Allogeneic Stem Cell Transplantation for Chronic Myelomonocytic Leukemia: A Report From the Societe Francaise De Greffe De Moelle Et De Therapie Cellulaire. Eur J Haematol (2013) 90:355-64. doi: 10.1111/ ejh. 12073

45. Symeonidis A, van Biezen A, de Wreede L, Piciocchi A, Finke J, Beelen D, et al. Achievement of Complete Remission Predicts Outcome of Allogeneic Haematopoietic Stem Cell Transplantation in Patients With Chronic Myelomonocytic Leukaemia. A Study of the Chronic Malignancies Working Party of the European Group for Blood and Marrow Transplantation. Br J Haematol (2015) 171:239-46. doi: 10.1111/bjh.13576

46. de Witte T, Bowen D, Robin M, Malcovati L, Niederwieser D, Yakoub-Agha I, et al. Allogeneic Hematopoietic Stem Cell Transplantation for MDS and CMML: Recommendations From an International Expert Panel. Blood (2017) 129:1753-62. doi: 10.1182/blood-2016-06-724500

47. Solary E, Itzykson R. How I Treat Chronic Myelomonocytic Leukemia. Blood (2017) 130:126-36. doi: 10.1182/blood-2017-04-736421

48. Robin M, Fenaux P. Hypomethylating Agents as Bridging Therapy Before Allogeneic Hematopoietic Stem Cell Transplantation in Patients With Chronic Myelomonocytic Leukemia? Biol Blood Marrow Transplant (2016) 22:1-2. doi: 10.1016/j.bbmt.2015.11.004

49. Potter VT, Iacobelli S, van Biezen A, Maertens J, Bourhis JH, Passweg JR, et al. Comparison of Intensive Chemotherapy and Hypomethylating Agents Before Allogeneic Stem Cell Transplantation for Advanced Myelodysplastic Syndromes: A Study of the Myelodysplastic Syndrome Subcommittee of the Chronic Malignancies Working Party of the European Society for Blood and Marrow Transplant Research. Biol Blood Marrow Transpl (2016) 22:1615-20. doi: 10.1016/j.bbmt.2016.05.026

50. Kongtim P, Popat U, Jimenez A, Gaballa S, El Fakih R, Rondon G, et al. Treatment With Hypomethylating Agents Before Allogeneic Stem Cell Transplant Improves Progression-Free Survival for Patients With Chronic Myelomonocytic Leukemia. Biol Blood Marrow Transpl (2016) 22:47-53. doi: 10.1016/j.bbmt.2015.08.031

51. Fenaux P, Jouet JP, Bauters F. Low-Dose Cytosine Arabinoside in Adult Chronic Myelomonocytic Leukemia. J Clin Oncol (1987) 5:1129-30.

52. Cheson BD, Jasperse DM, Simon R, Friedman M. A Critical Appraisal of LowDose Cytosine Arabinoside in Patients With Acute Non-Lymphocytic Leukemia and Myelodysplastic Syndromes. J Clin Oncol (1986) 4:1857-64. doi: 10.1200/JCO.1986.4.12.1857
53. Oscier D, Worsley A, Hamblin T, Mufti G. Treatment of CMML With Low Dose Etoposide. Br J Haematol (1989) 72:468-71. doi: 10.1111/j.13652141.1989.tb07735.x

54. Wattel E, Guerci A, Hecquet B, Economopoulos T, Copplestone A, Mahé B, et al. A Randomized Trial of Hydroxyurea Versus VP16 in Adult Chronic Myelomonocytic Leukemia. Groupe Francais Des Myelodysplasies and European CMML Group. Blood (1996) 88:2480-7. doi: 10.1182/blood. V88.7.2480.bloodjournal8872480

55. Pleyer L, Germing U, Sperr WR, Linkesch W, Burgstaller S, Stauder R, et al. Azacitidine in CMML: Matched-Pair Analyses of Daily-Life Patients Reveal Modest Effects on Clinical Course and Survival. Leuk Res (2014) 38:475-83. doi: 10.1016/j.leukres.2014.01.006

56. Itzykson R, Santini V, Chaffaut C, Adès L, Thepot S, Giagounidis A, et al. The American Society of Hematology_ 62nd Annual Meeting and Exposition. Decitabine Versus Hydroxyurea for Advanced Proliferative CMML: Results of the EMSCO Randomized Phase 3 DACOTA Trial. Blood (2020) 136:53-4. doi: 10.1182/blood-2020-138680

57. Renneville A, Patnaik MM, Chan O, Padron E, Solary E. Increasing Recognition and Emerging Therapies Argue for Dedicated Clinical Trials in Chronic Myelomonocytic Leukemia. Leukemia (2021) 35:2739-51. doi: 10.1038/s41375-021-01330-1

58. Pei S, Pollyea DA, Gustafson A, Stevens BM, Minhajuddin M, Fu R, et al. Monocytic Subclones Confer Resistance to Venetoclax-Based Therapy in Patients With Acute Myeloid Leukemia. Cancer Discov (2020) 10:536-51. doi: 10.1158/2159-8290.CD-19-0710

59. Carr RM, Vorobyev D, Lasho T, Marks DL, Tolosa EJ, Vedder A, et al. RAS Mutations Drive Proliferative Chronic Myelomonocytic Leukemia via a KMT2A-PLK1 Axis. Nat Commun (2021) 12:2901. doi: 10.1038/s41467021-23186-W

60. Montalban-Bravo G, Hammond D, DiNardo CD, Konopleva M, Borthakur G, Short NJ, et al. Activity of Venetoclax-Based Therapy in Chronic Myelomonocytic Leukemia. Leukemia (2021) 35:1494-99. doi: 10.1038/ s41375-021-01240-2

Conflict of Interest: The authors declare that the research was conducted in the absence of any commercial or financial relationships that could be construed as a potential conflict of interest.

Publisher's Note: All claims expressed in this article are solely those of the authors and do not necessarily represent those of their affiliated organizations, or those of the publisher, the editors and the reviewers. Any product that may be evaluated in this article, or claim that may be made by its manufacturer, is not guaranteed or endorsed by the publisher.

Copyright (C) 2021 Liapis and Kotsianidis. This is an open-access article distributed under the terms of the Creative Commons Attribution License (CC BY). The use, distribution or reproduction in other forums is permitted, provided the original author(s) and the copyright owner(s) are credited and that the original publication in this journal is cited, in accordance with accepted academic practice. No use distribution or reproduction is permitted which does not comply with these terms. 